\title{
Growth, sexual development and menstrual issues among girls with cerebral palsy - A cross sectional study in a tertiary care centre
}

\author{
Arathi P. Rao ${ }^{\mathrm{a}, *}$, Hitesh Shah ${ }^{\mathrm{b}}$, Shyamala Guruvare ${ }^{\mathrm{c}}$, Vasudev Guddattu ${ }^{\mathrm{d}}$ \\ a Prasanna School of Public Health, Manipal Academy of Higher Education, Manipal, India \\ ${ }^{\mathrm{b}}$ Department of Orthopaedics, Manipal Academy of Higher Education, Manipal, India \\ ${ }^{\mathrm{c}}$ Department of OBG, Manipal Academy of Higher Education, Manipal, India \\ d Department of Statistics, Prasanna School of Public Health, Manipal Academy of Higher Education, Manipal, India
}

\section{A R T I C L E I N F O}

\section{Keywords:}

Puberty

Sexual development

Menstruation

Cerebral palsy

\begin{abstract}
A B S T R A C T
Introduction: There is paucity of literature and research on puberty among girls with cerebral palsy especially from India. Knowledge of sexual development and menstrual issues can guide towards better care for these girls. Objective: To study the onset of sexual development and patterns of menstrual issues among girls with cerebral palsy who attended cerebral palsy clinic.

Methods: A cross sectional study of 93 girls with cerebral palsy(GMFCS levels-I toV), aged 5-19 years, attending the cerebral palsy clinic at a tertiary care hospital, was conducted. Data was obtained by interviewing the parents of the girls with cerebral palsy using a semi structured questionnaire followed by examination of the girls.

Results: Mean age of the girls in the study was $11.27 \pm 4.46$ yrs. The average height of the girls with cerebral palsy were found to be lesser than the published standards. 36(38.7\%) girls had attained menstruation. Average age of menarche was $12.54 \pm 1.37 y$ yrs. There was one case of delayed puberty. $75 \%$ of the girls had regular cycles while $47.2 \%$ had dysmenorrhoea. $69.4 \%$ used sanitary pads and mothers changed the pads in $38.8 \%$ of the girls. $58.3 \%$ of them had signs of vaginal infection while $25 \%$ of them showed signs of premenstrual syndrome. Conclusion: Girls with cerebral palsy required extra support from their care-givers during the menstrual cycles. Usage of sanitary pads was not widely prevalent with signs of vaginal infection. Breast development was delayed but pubic hair development was found earlier among the study participants.
\end{abstract}

\section{Introduction}

Cerebral palsy (CP) is a group of syndromes that arise due to developmental anomalies or lesions in the brain characterised by grades of motor impairment. It is diagnosed in 1-3 per 1000 children and associated with physical as well as mental disability in certain cases. Puberty is the transitional phase which is associated with physical body growth, sexual maturity and mental changes which help shape the young adult. ${ }^{1}$

Girls with CP have limited capacity to cope with issues like menstrual hygiene, pain abdomen (dysmenorrhoea) which can manifest as behavioural changes, heavy bleeding, irregular cycles, infections due to their restricted mobility compounded by lack of comprehension. ${ }^{2}$ In children with $\mathrm{CP}$, puberty can pose new demands and concerns on the girls, parents and caregivers with the onset of menstruation (menarche). ${ }^{3-5}$
Studies in the West have reported earlier onset of puberty in children with $\mathrm{CP} .{ }^{6}$ However, there is a paucity of studies on sexual development and menstrual issues among girls with cerebral palsy especially in the Indian scenario. ${ }^{7}$ Studies have reported that routine gynaecological care has been lacking among adolescents and adults with disabilities unwary of their sexual needs. ${ }^{3,6,8,9}$ Appropriate management of menstrual issues in these girls with $\mathrm{CP}$, can help relieve the burden of care givers and help them adopt suitable strategies to address the issues. $^{10,11}$ This can be possible when adequate data is made available regarding the nature of the problem in this special population. Early recognition of $\mathrm{CP}$ and appropriate referrals can help institute rehabilitative measures earlier so that children with lower levels of $\mathrm{CP}$ can be relatively independent at the time of puberty. The present study will help identify the pattern of onset of sexual development, menstrual patterns and issues associated with menstruation in a specialised clinic setting run exclusively for children with cerebral palsy.

\footnotetext{
* Corresponding author. Prasanna School of Public Health, Manipal Academy of Higher Education, Old TAPMI Building, II floor, Manipal, 576104 Udupi, Karnataka, India.

E-mail address: arathimph@gmail.com (A.P. Rao).
} 


\subsection{Materials and methods}

The present study was designed to assess the sexual development and menstrual issues among girls with $\mathrm{CP}$, both inpatients as well as outpatients, who attended the cerebral palsy clinic in a tertiary care hospital. Most of these patients do not visit a community health centre due to lack of infrastructure and skills to address their health problems. It was noticed that gynaecological advice was never sought for by the parents of these girls. A cross sectional study was conducted among girls with cerebral palsy between October 2016 to November 2017 with Gross Motor Function Classification System (GMFCS) levels I to V. ${ }^{12}$ It uses an ordinal scale to classify the gross motor function of the child with CP based on typical performance like sitting, standing, walking activities and use of mobility aids. ${ }^{13}$ It ranges from level 1 when the child is capable of independent movement without support to level 5 where the child is wheel chair with no neck control and totally dependent for daily activities. The sample size was calculated based on anticipated prevalence of inadequate menstrual hygiene of $60 \%$ revealed by a pilot study conducted among 10 girls with $\mathrm{CP}$ attending the $\mathrm{CP}$ clinic which functions once in a week. With a margin of error of $10 \%$, a sample of 93 girls were included for the present study. All girls in the age group of 5-19 years, who attended the CP clinic at the tertiary hospital during the study period were included with a view of detecting any signs of precocious puberty among the study participants even as early as 5 years. ${ }^{14}$ On an average about 3-4 new cases of children with $\mathrm{CP}$ attend the clinic every week. Out of them 1-2 were girls meeting the inclusion criteria. A total of 95 participants were approached for the study out of which parents of 2 girls refused to participate. Among those who were willing, the nature and purpose of the study was explained to the parents and informed consent was obtained prior to the study. In case the child was equal to or greater than 13 years, an assent was also obtained. A standardised, pilot tested and validated semi-structured questionnaire was used for the interview of the parents. Open ended questions were included to provide an opportunity for the parents to provide any other observations regarding menstrual issues. Both the parents were invited to participate in the interview. In most of the cases it was the mothers who provided the information but the interview was given even when fathers only were present. Even though the parents had visited the clinic for orthopaedic needs, it was found that they were willing to participate to provide the required information. Data was collected regarding socio-demographic information, age of onset of breast and pubic hair development, signs of precocious puberty, behavioural changes if any. Among those who had attained menarche, details of onset of menstruation, number of days of flow, regularity of cycles, presence of dysmenorrhoea and its management, type of menstrual product used, were obtained. Information regarding any signs of vaginal infection and lack of menstrual hygiene were objectively obtained during the interview. Height and weight of the participants were measured using standardised and validated instruments. IQ assessment of all children attending the CP clinic is regularly conducted at the Clinical Psychology department of the hospital which was noted. Breast examination and examination of pubic hair development for Tanner's staging was done after explaining the procedure to the accompanying care giver and obtaining the consent. Data was analysed using Statistical Package for Social Sciences version 16 and results were summarised as frequencies and proportions. Ethical clearance for the present study was obtained from the Institutional Ethical Committee.

\subsection{Results}

In the present study the mean age of the participants was found to be $11.27 \pm 4.46$ yrs. The socio-demographic information of the participants is as shown in Table $1.71 \%$ of the participants were hindus. Majority of the mothers (30.1\%) and fathers (36.6\%) studied only till high school. $79.6 \%$ of the mothers were unemployed and most of them preferred to stay at home to look after the girl child. Among $77.4 \%$ of the participants, mother was the primary caregiver of the child. In $19.4 \%$, a family member helped the biological parent to care for the girl child at home. $3.2 \%$ were cared by a relative only. $92.5 \%$ of the parents reported non-consanguinous marriage. Table 2 shows the Gross Motor Functional Classification System of the study participants and it was found that $35.5 \%$ of them were in level 1 who were capable of independent movement where as $4.3 \%$ of them were in level 5 who were wheel chair bound and totally dependent for their daily needs. The average BMI of the participants was found to be $17.35 \pm 4.02$ and the average IQ was found to be $72.42 \pm 2.93$.

The average height of the participants across the ages have been shown in Table 3 along with the standard height among normal Indian girls at $50^{\text {th }}$ percentile as per the cross sectional published by ICMR. ${ }^{15}$ It was found that the mean height of the participants across the age groups were lesser compared to their normal counterparts across the same ages.It was possible to measure the height of only 86 participants while the remaining girls were in level 4 and 5 GMFCS and were wheel chair bound. They were seen as outpatients not willing to wait till the height could be checked.

The mean age of onset of breast development among the girls was $11.07 \pm 3.13$ years and that of pubic hair development was $11.52 \pm 2.43$ years. $36(38.7 \%)$ girls had attained menarche and the average age of onset of menstruation was $12.54 \pm 1.37$ years in the present study. Only one participant gave history of delayed menarche with onset of menstruation after 17 years of age while there was no case of precocious puberty found in the present study. $25 \%$ of the girls gave history suggestive of premenstrual syndrome. Menstrual cycles occurring between 21 and 35 days with a flow of $2-5$ days are considered regular. ${ }^{16} 75 \%$ of the girls had regular cycles ranging between 28 and 35 days. $80.6 \%$ of the girls had normal menstrual flow for 3-5 days while 5 girls (13.6\%) reported bleeding for more than 7 days and associated with clots. Only 1 girl received hormonal management while the rest of the parents reported of having not taken any gynaecological advice for the same. $17(47.2 \%)$ of the girls suffered from dysmenorrhoea during the cycles. Among them 10 (58.8\%) of them took rest only as reported by the mothers because they didn't want the child to take tablets for the same. $69.4 \%$ of the girls used sanitary pads during the cycles while the remaining used cloth. The most common reason given by the mothers were they had no place to safely dispose the napkins or were not aware how to do the same. Mothers helped change the sanitary pads in $38.9 \%$ of the participants and only one child was reported to be intolerant to sanitary pads during menstruation. In the present study, it was found that some form of vaginal infection was found in $58.3 \%$ (21) of the participants and the most common complaint was white discharge per vagina (71.4\%) (Table 4).

\section{Discussion}

In the present study the mean age of the participants was found to be $11.27 \pm 4.46$ yrs. This was different from the study by Zacharin et al. where the average of the participants was 15.11 years. ${ }^{11}$ In another study by Worley et al. conducted to assess secondary sexual characteristics among children with $\mathrm{CP}$, the mean age of the participants was found to be 9.6 years. ${ }^{17}$ In another study by Grover, the average age of the participants with intellectual disability who had consulted for gynaecological advice was 15.9 years. ${ }^{18}$

The mean age of menarche was $12.54 \pm 1.37$ years in the current study. This was similar to the study by Zacharin et al. where the average age of menarche was 12.3 years. ${ }^{11}$ Also similar to the study by Dizon et al. showed that the average age of menarche among the participants with developmental delay was 12.13 years and by Burke et al. which revealed the mean age of menarche to be $12.5 \pm 2$ years. ${ }^{3,5}$ However this was found to be different by a study by Nancy Murphy et al. which showed that the median age of menarche of girls with CP in US 14.0 years. ${ }^{6}$ The study by Cento et al. showed that the mean age of menarche 
among girls with mental retardation was $11.6 \pm 0.7$ years. ${ }^{19}$

The mean age of pubic hair development for Indian girls is 13.6 years as per the IAP textbook of Pediatrics while in the present study the mean age of $11.52 \pm 2.43$ years which is slightly earlier. ${ }^{14}$ In contrast, the mean age of breast development for normal Indian girls has been reported as 10.5 years which was found to be slightly delayed in the present study.

In the present study the average height of the participants in every year age groups were found to be comparable to the observations in the study by Baidwan et al., except in the 16th year age group. ${ }^{7}$ This possible could be due to very less number of girls in this age among the participants.

The current study revealed that $61.2 \%$ of the girls were premenarcheal. This was higher compared to the study by Dizon et al. which revealed that $43 \%$ of the girls with developmental delay were premenarcheal and parents have sought more information regarding how to deal with menstrual issues in such children. ${ }^{5}$

In the present study, $35.5 \%$ of the girls with $\mathrm{CP}$ were found to be in GMFCS level 1 . This is in contrast to the study by Worley et al. where $53 \%$ of the participants were in GMFCS level $5 .{ }^{16}$ In a study by Siddique et al. it was reported that signs of precocious puberty was found in girls with neurodevelopmental delay as early as 5 years 11 months. ${ }^{14}$ But in the present study none of the participants showed signs of or reported features of precocious puberty. Studies by Backeljaw et al. and Cento et al. have reported delayed puberty can also occur in adolescent girls with developmental delay and in the present there was one case of delayed puberty(onset at 17 years). ${ }^{19,20}$

The current study showed that $46.2 \%$ of the girls were in Tanner's stage 1 of breast development which is similar to the study by Kupperminc et al. where $45 \%$ of them were in Tanner's stage $1 .{ }^{21}$ In the study by Worley et al. it was found that $50 \%$ of the girls were in Tanner's stage 2 at 8.6 years but in the present study girls showed breast development of Tanner's stage 2 at 9 years and beyond. ${ }^{16}$

In the present study, $75 \%$ of the girls who had attained menarche had regular cycles and $25 \%$ of them had irregular cycles. This was different from the study by Dizon et al. which revealed that $44 \%$ of the girls had regular cycles while $41 \%$ had irregular cycles. ${ }^{5}$ Even though irregular cycles during first 2 years after menarche has been reported, in the present study girls had irregular cycles much later after menarche. ${ }^{6,10,22}$ This study also revealed that $21.9 \%$ of the girls had dysmenorrhoea while in the present study $47.2 \%$ of the girls had dysmenorrhoea.

\subsection{Conclusion}

The current study was the first of its kind in the present setting to understand the nature of sexual development and menstrual cycles of girls who had cerebral palsy. Even though deviations in age of onset of puberty was not seen in the present group of participants menstrual issues like irregular cycles, heavy bleeding and dysmenorrhoea were present. Parents have not opted for any medical advice in most of the cases and the possible reason could be that they are not hopeful of the future reproductive career of their girls. Lack of menstrual hygiene with prevalence of vaginal infections would need expert advice to prevent further complications in these girls. Parents also need to be educated regarding these issues about their children to realise importance of the same.

\subsection{Limitations}

Study included girls attending a CP clinic in a private sector tertiary care hospital only.

\section{Conflicts of interests}

The authors have none to declare.

\section{Acknowledgements}

We are grateful to Manipal Academy of Higher Education for permitting to conduct the study in the $\mathrm{CP}$ clinic as well as providing eresources for the present study.

\section{Appendices}

Table 1

Socio-demographic information of the participants in the study.

\begin{tabular}{lll}
\hline Variables & Frequency & Percentage (\%) \\
\hline Monthly income & & \\
Less than 10,000 & 35 & 37.6 \\
10,000-20,000 & 58 & 62.4 \\
$\quad$ 20,000 & 00 & 0.0 \\
Religion & & \\
Hindu & 66 & 71.0 \\
Christian & 05 & 5.4 \\
Muslim & 22 & 23.6 \\
Mother's education & & \\
Illiterate & 6 & 6.5 \\
Primary & 16 & 17.1 \\
High school & 28 & 30.1 \\
Pre- University & 21 & 22.6 \\
Graduation & 17 & 18.3 \\
Postgraduation & 5 & 5.4 \\
Father's education & & \\
Illiterate & 8 & 8.6 \\
Primary & 12 & 12.9 \\
High school & 34 & 36.6 \\
Pre- University & 22 & 23.6 \\
Graduation & 11 & 11.8 \\
& & (continued on next page)
\end{tabular}


Table 1 (continued)

\begin{tabular}{lll}
\hline Variables & Frequency & Percentage (\%) \\
\hline $\begin{array}{l}\text { Postgraduation } \\
\text { Family type }\end{array}$ & 6 & 6.5 \\
$\quad$ Nuclear & 70 & 75.7 \\
Joint & 5 & 5 \\
Extended & 18 & 19.3 \\
\hline
\end{tabular}

Table 2

Distribution of the participants across the GMFCS levels.

\begin{tabular}{lll}
\hline GMFCS level of CP & Frequency (n) & Percentage (\%) \\
\hline Level 1 & 33 & 35.5 \\
Level 2 & 18 & 19.4 \\
Level 3 & 21 & 22.6 \\
Level 4 & 17 & 18.3 \\
Level 5 & 4 & 4.2 \\
Total & 93 & 100.0 \\
\hline
\end{tabular}

Table 3

Comparison of mean height of the participants with the $50^{\text {th }}$ centile height of their normal counterparts as per ICMR.

\begin{tabular}{llll}
\hline Age (yrs) & $\mathrm{n}$ & Mean \pm SD $(\mathrm{cms})$ & $50^{\text {th }}$ percentile Height of Indian girls in cms $(6-17$ yrs $)$ \\
\hline $5-5.5$ & 5 & $98.6 \pm 4.27$ & \\
$6-6.5$ & 15 & $100.91 \pm 8.35$ & 114.9 \\
7 & 5 & $98.9 \pm 8.24$ & 117.4 \\
$8-8.5$ & 6 & $120.3 \pm 10.87$ & 126.2 \\
9 & 5 & $113.3 \pm .13 .80$ & 129.2 \\
10 & 7 & $119.4 \pm 11.07$ & 135.2 \\
11 & 5 & $131.0 \pm 20.29$ & 140.9 \\
12 & 9 & $136.44 \pm 5.57$ & 146.0 \\
13 & 3 & $141.33 \pm 3.05$ & 150.4 \\
14 & 4 & $148.75 \pm 4.99$ & 153.8 \\
15 & 7 & $146.93 \pm 7.03$ & 156.8 \\
16 & 2 & $139.75 \pm 8.13$ & 157.0 \\
17 & 4 & $142.38 \pm 1.49$ & \\
18 & 3 & $142.0 \pm 17.05$ & \\
19 & 6 & $146.50 \pm 6.05$ & \\
\end{tabular}

Table 4

Distribution of the participants regarding the menstrual issues.

\begin{tabular}{lll}
\hline Menstrual details & Frequency & Percentage (\%) \\
\hline Nature of menstrual cycles & & 75 \\
$\quad$ Regular & 27 & 25 \\
$\quad$ Irregular & 09 & 80.6 \\
Duration of bleeding & 29 & 13.6 \\
$\quad$ Normal & 5 & 5.8 \\
$\quad$ Heavy bleeding & 2 & \\
$\quad$ Less bleeding & 17 & 47.2 \\
Presence of dysmenorrhoea & 19 & 52.8 \\
$\quad$ Yes & \multicolumn{2}{l}{}
\end{tabular}


Table 4 (continued)

\begin{tabular}{lll}
\hline Menstrual details & Frequency & Percentage (\%) \\
\hline Only rest & 10 & 58.8 \\
Hormonal & 1 & 5.9 \\
Non- hormonal tablets & 6 & 35.3 \\
Type of menstrual product used & & \\
$\quad$ Sanitary pads & 25 & 69.4 \\
$\quad$ Cloth & 11 & 30.6 \\
Any sign of vaginal infection: & & \\
$\quad$ Yes & 21 & 58.8 \\
No & 15 & 41.2 \\
Type of infection: (n=21) & & \\
Presence of white discharge & 15 & 71.44 \\
$\quad$ Itching & 4 & 19.04 \\
$\quad$ Burning urine & 2 & 9.52 \\
\hline
\end{tabular}

\section{References}

1. Zaccharin M. Puberty, contraception and hormonal management in children with developmental disabilities. Clin Pediatr. 2009;48:149.

2. Albanese A, Hopper N. Suppression of menstruation in adolescents with severe learning disabilities. Arch Dis Child. 2007;92(7):629-632.

3. Burke L, Kalpakjian C, Smith Y, Quint E. Gynecologic issues of adolescents with down syndrome, autism, and cerebral palsy. J Pediatr Adolesc Gynecol. 2010;23(1):11-15.

4. Grover SR. Menstrual and contraceptive management in women with an intellectual disability. Med J Aust. 2002;176:108-110

5. Dizon CD, Allen LM, Ornstein MP. Menstrual and contraceptive issues among young women with developmental delay: a retrospective review of cases at the Hospital for Sick Children, Toronto. J Pediatr Adolesc Gynecol. 2005;18 157-62.

6. Murphy N, Elias E. Sexuality of children and adolescents with developmental disabilities. Pediatrics. 2006;118(1):398-403.

7. Baidwan S, Chhatwal J, Paul M, Deswal R. Growth and sexual maturity pattern of girls with mental retardation. Int J App Basic Med Res. 2014;4(1):38.

8. Weppner DM, Brownscheidle CM. The evaluation of the health care needs of women with disabilities. Prim Care Update OB/GYNS. 1998;5:210.

9. Neufeld JA, Klingbeil F, Bryen DN, Silverman B, Thomas A. Adolescent sexuality and disability. Phys Med Rehabil Clin. 2002;13:857-873.

10. Quint E. Opinions in pediatric and adolescent gynecology. The conservative management of abnormal uterine bleeding in teenagers with developmental disabilities. $J$ Pediatr Adolesc Gynecol. 2003;16:51.

11. Zacharin M, Savasi I, Grover S. The impact of menstruation in adolescents with disabilities related to cerebral palsy. Arch Dis Child. 2010;95(7):526-530.
12. Paneth N, Hong T, Korzeniewski S. The descriptive epidemiology of cerebral palsy. Clin Perinatol. 2006;33(2):251-267.

13. Rethlefsen SA, Ryan DD, Kay RM. Classification systems in cerebral palsy. Orthop Clin N Am. 2010;41:457-467

14. Siddiqi SU, Van Dyke DC, Donohoue P, McBrien DM. Premature sexual development in individuals with neurodevelopmental disabilities. Dev Med Child Neurol. 1999;41:392-395.

15. Agarwal KN. Growth and sexual development in puberty. IAP Textbook of Pediatrics. fifth ed. Gwalior: Jaypee Brothers Medical Publishers; 2013.

16. Mudaliar AN, Menon MKK. Anatomy and physiology. Clinical Obstetrics. tenth ed. Chennai: Orient Longman Pvt Ltd Publishers; 2005.

17. Worley G, Houlihan C, Herman-Giddens M, et al. Secondary sexual characteristics in children with cerebral palsy and moderate to severe motor impairment: a crosssectional survey. Pediatrics. 2002;110(5):897-902.

18. Grover SR. Menstrual and contraceptive management in women with intellectual disability. Med. Community, MJA. 2001(176):108-110.

19. Cento RM, Ciampelli M, Proto C, Le Donne M, Romano C, Lanzone A. Neuroendocrine features of pubertal development in females with mental retardation. Gynecol Endocrinol. 2001;15:178-183.

20. Backeljauw P, Rose S, Lawson M. Clinical management of menstruation in adolescent females with developmental delay. Endocrinololgist. 2004;14(2):87-92.

21. Kuperminc MN, Gurkha MJ, Houlihan CM, Henderson RC, Roemmich JN, Rogol AD, et al. Puberty, statural growth and growth hormone release in children with cerebral palsy. Pediatr Rehabil Med. 2009;2(2):131-141.

22. Quint EH. Gynecological care for teenagers with disabilities. J Pediatr Adolesc Gynecol. 2003;16:115-117. 